\title{
Penetration capability of three different light curing units to composite-resin as measured by radiometer
}

\author{
Henri Hartman* \\ Department of Pedodontics, Dentistry Study Programme, General Achmad Yani University, Indonesia
}

\begin{abstract}
Introduction: Composite-resin are widely used as restorative material in dental practice on daily basis, when it comes to an aesthetic consideration. The purpose of this study is to investigate and compare the light penetration capabilities of three light curing units (LCU) through layers of composite resin using a radiometer. Method: Composites resin discs ( $2 \mathrm{~mm}$ thick with $8 \mathrm{~mm}$ diameter) were cured out of seven different shades. Each speciments were used as barrier, and light source from three different LCUS were then applied through it. Radiometer was used to record the intensities of each LCU. Result: LED.C (Woodpecker ${ }^{T M}$ ) has the lowest penetration capabilities to pass through the barrier compare to all LCU. The output intensity $\left(\mathrm{mW} / \mathrm{cm}^{2}\right)$ of all LCU has decrease gradually. ANOVA test showed that there was significant result $(p<0.01)$ for each speciment. Conclusion: The differences composite-resin shade could decrease the penetration capability of LCU.
\end{abstract}

Keywords: Light Curing Unit, light intensity radiometer, composite-resin,

p-ISSN: 1979-0201; e-ISSN: 2549-6212; Available from: http://jurnal.unpad.ac.id/pid/article/view/18326

DOI: http://dx.doi.org/10.24198/pid.vol30no2.18326

Submission: January 8, 2018; Accepted: April 27, 2018; Published online: July 31, 2018

\section{INTRODUCTION}

Composite-resin is the most often material that dentist use for best aesthetic tooth restoration. It's activated with photo polymerization techniques. Each composite-resin has their own characteristic and should be cure with appropriate light intensity $\left(\mathrm{mW} / \mathrm{cm}^{2}\right) .{ }^{1,2}$

Light-emitting diode (LED) and halogen are light curing unit that widely used for dental composite polymerization. It's reported that not all dental composite suitable with LED curing because the spectra of LED is differ from halogen units and the composite resin need to be adjusted to get better result. ${ }^{3}$

Composite-resin has some disadvantages such as polymerization shrinkage, humidity environment that difficult to handle, and color instability. ${ }^{3,4}$ To avoid composite-resin disadvantages, dentist should understanding the manipulation technique of its material properties. Most light-polymerized composite- resin contain a camphoroquionone, which initiates polymerization by breaking down into free radicals when exposed to light in the blue spectrum at wavelengths 400 $500 \mathrm{~nm}$ range. ${ }^{5,6}$ composite-resin failure is not only

Corresponding author: Henri Hartman, Department of Pedodontics, Dentistry Study Programme, Unjani Terusan Jendral Sudirman Cimahi, 40285 Indonesia; Phone: +62 812-2153-445; email: henri.hartman@lecture.unjani.ac.id 
come from the material components, but could be come from inappropriate technique or method of placement of restoration, and inadequate polymerization. $^{7}$

Composite-resin polymerization could be done by light curing unit (LCU). The first generation of LCU are quart-tungsten-halogen (QTH) lamps that operate with white halogen bulb and now varry to laser light, plasma arc, or LED. Dental LED lights typically use indiumgallim-nitride semiconductors that produce a blue light. ${ }^{8}$ LED demonstrated advantages in preventing overheating and achieving highly efficient dental composite polymerization. ${ }^{3,4,8}$ It doesn't produce alot of heat compared to QTH units and could achieve energy range between 450-490 $\mathrm{nm}$ for ideal activating materials that use camphorquinone as initiator. ${ }^{4}$

Energy densities $\left(\mathrm{mWs} / \mathrm{cm}^{2}\right)$ in the product of light intensity and irradiation time, have been suggested to account for variation in irradiation intensity, time and mode. ${ }^{5}$ Light units less than $300 \mathrm{~mW} / \mathrm{cm}^{2}$ is not recommended. It will create inadequate polymerization of composite-resin. Light-curing units at lower power density level would decrease the mechanical properties of some resin-based composites. ${ }^{5,9}$ The best method for evaluation of the LCU intensities output is using a radiometer. Fortunately, some newer LCU have a radiometer included the buying package. ${ }^{9}$

Some reports have shown that many dentist lights have inadequate output intensity. In the other hand they satisfied enough with the product. Prolonged irradiation time (curing time) may compensate the curing problem. ${ }^{7,10}$ There's some factors that influenced tooth restoration with composite-resin, inlcude depth of cure, light intensity, exposure time, composite material, size, opacity, and shade..$^{11-13}$ This aim of study was to investigate the capabilty of light curing unit to penetrate composite-resin using radiometer.

\section{METHODS}

The speciments was build in $2 \mathrm{~mm}$ thickness and $8 \mathrm{~mm}$ diameter (Figure 1. A). There's seven shade composite resin used in this study (Dentsply ${ }^{\mathrm{TM}}$, Ceram-X mono M1, M2, M3, M4, M5, M6, M7). All composite resin were cured with Demi Light $\left(K{ }^{T M}\right)$ for 5 seconds from top and bottom part On the surface of the barrier, To polymerize the speciments in same shape and size.

Three Light Curing units was used as a comparation, there's Valo(Ivoclar $\left.{ }^{\mathrm{TM}}\right)$, Demi Light $\left(\right.$ Kerr $^{\mathrm{TM}}$ ), and LED.C (Woodpecker ${ }^{\mathrm{TM}}$ ). Each LCU were checked 20 times with MaxLED radiometer for the peak output intensity $\left(\mathrm{mW} / \mathrm{cm}^{2}\right)$ before used(Table 1).

All speciments was used separately as a barrier in radiometer to check the capability of light curing unit to penetrate different compositeresin shade (Figure 1. B). The LCU was used 20 times curing in every speciment and recorded. Curing times was set in fastest mode (Valo $=3$ second standar mode, Demi Light $=5$ second, LED. $C=5$ second).

LCU tip was positioned on the surface of the barrier, and started curing in same position untill

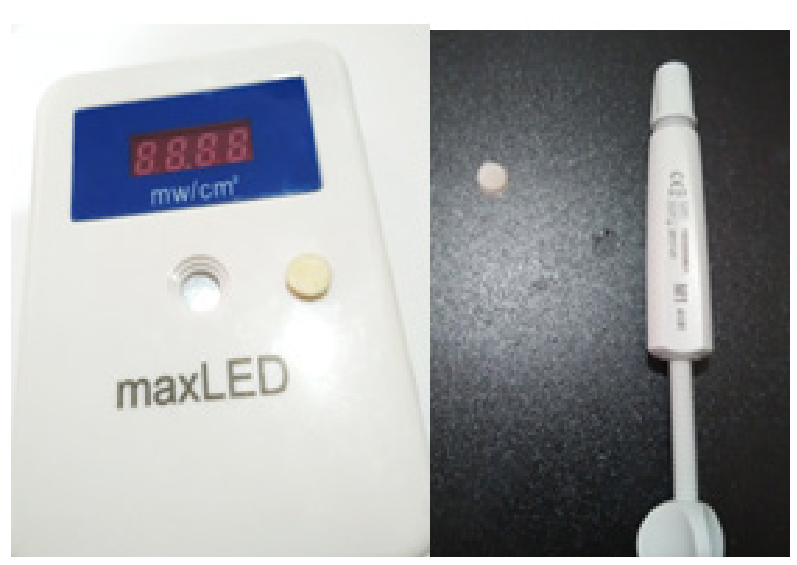

A

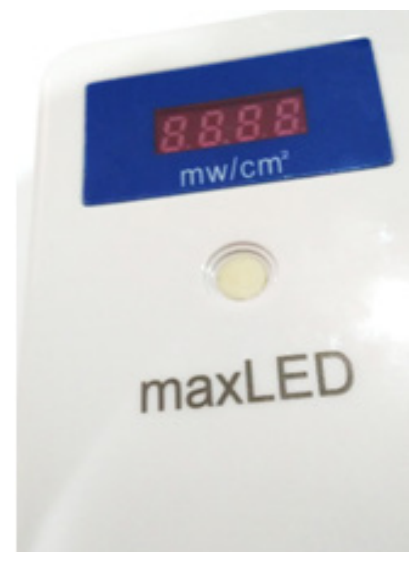

B

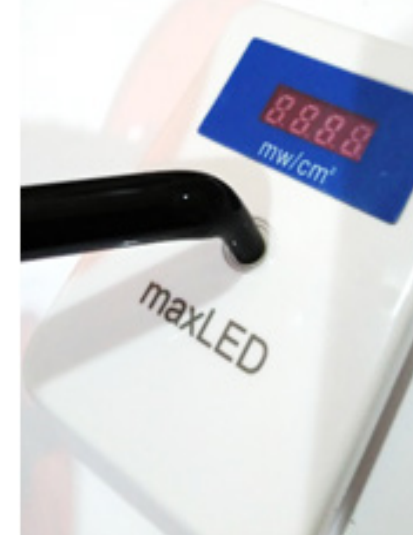

C

Figure 1. A. Speciment shape with $2 \mathrm{~mm}$ thickness and $8 \mathrm{~mm}$ diameter; B. Speciment was used as a barrier in radiometer; C. Light Curing Unit (LCU) tip position. 
Table 1. Output intensity result of three LCU without any barrier (20 times curing application- $\mathrm{mW} / \mathrm{cm}^{2}$ ).

\begin{tabular}{cccc}
\hline \multirow{2}{*}{ No. of curing } & \multicolumn{3}{c}{ Without barrier } \\
\cline { 2 - 4 } & DEMI PLUS & VALO & LED.C \\
\hline 1 & 1650 & 2800 & 1700 \\
2 & 1850 & 2800 & 1650 \\
3 & 1800 & 2800 & 1700 \\
4 & 1700 & 2800 & 1700 \\
5 & 1750 & 2800 & 1700 \\
6 & 1800 & 2800 & 1750 \\
7 & 1800 & 2800 & 1700 \\
8 & 1800 & 2800 & 1700 \\
9 & 1850 & 2800 & 1700 \\
10 & 1800 & 2800 & 1650 \\
11 & 1700 & 2800 & 1650 \\
12 & 1700 & 2800 & 1600 \\
13 & 1750 & 2800 & 1600 \\
14 & 1650 & 2800 & 1600 \\
15 & 1700 & 2800 & 1600 \\
16 & 1700 & 2800 & 1600 \\
17 & 1700 & 2800 & 1650 \\
18 & 1700 & 2800 & 1600 \\
19 & 1700 & 2800 & 1650 \\
20 & 1700 & 2800 & 1600 \\
Mean & 1740 & 2800 & 1655
\end{tabular}

end of the test (Figure 1. C). There's no special holder for each curing but fixed at same position during the test. Statistical analysis of the data was performed using one-way analysis of variance (ANOVA) and t-test.

\section{RESULTS}

Without any barrier on radiometer, the highest output intensity was shown by Valo LCU (2800 $\left.\mathrm{mW} / \mathrm{cm}^{2}\right)$, meanwhile the lowest intensity was shown by LED.C (1655 $\left.\mathrm{mW} / \mathrm{cm}^{2}\right)$ (Table 1$)$.

After several test with different composite resin shade, the output intensity of all LCU has

Table 2. T- test in Demi Plus LCU without barrier and with the specimens

$\begin{array}{cccccc}\text { Sample } & \mathrm{n} & \text { Mean } & \text { std } & \mathrm{t} \text { test } & \mathrm{p} \text {-value } \\ \text { W-M1 } & 20 & 1347.50 & 59.55 & 101.20 & \\ \text { W-M2 } & 20 & 1350.00 & 64.89 & 93.04 & \\ \text { W-M3 } & 20 & 1310.00 & 50.26 & 116.56 & \\ \text { W-M4 } & 20 & 1455.00 & 60.48 & 107.59 & <0.01 \\ \text { W-M5 } & 20 & 1505.00 & 66.69 & 100.93 & \\ \text { W-M6 } & 20 & 1590.00 & 61.98 & 114.72 & \\ \text { W-M7 } & 20 & 1545.00 & 60.48 & 114.24 & \end{array}$

Table 3. T-test in Valo LCU and Woodpecker LCU without barrier and with the specimens

\begin{tabular}{|c|c|c|c|c|c|}
\hline \multirow{2}{*}{ Sample } & \multirow{2}{*}{$\mathrm{n}$} & \multicolumn{4}{|c|}{ T-test in Valo LCU } \\
\hline & & Mean & std & $\mathrm{t}$ test & $\mathrm{p}$-value \\
\hline W-M1 & 20 & 1735.00 & 46.17 & 168.06 & \\
\hline W-M2 & 20 & 1915.00 & 51.55 & 166.12 & \\
\hline W-M3 & 20 & 1810.00 & 41.68 & 194.23 & \\
\hline W-M4 & 20 & 2047.50 & 52.50 & 174.40 & $<0.01$ \\
\hline W-M5 & 20 & 2212.50 & 45.52 & 217.35 & \\
\hline W-M6 & 20 & 2310.00 & 52.82 & 195.60 & \\
\hline W-M7 & 20 & 2357.50 & 59.11 & 178.38 & \\
\hline
\end{tabular}

\begin{tabular}{cccc}
\multicolumn{4}{c}{ T-test in Woodpecker LCU } \\
Mean & std & t test & p-value \\
1382.50 & 61.29 & 100.88 & \\
1392.50 & 43.75 & 142.33 & \\
1350.00 & 45.88 & 131.58 & \\
1410.00 & 52.82 & 119.39 & $<0.01$ \\
1455.00 & 48.40 & 134.45 & \\
1505.00 & 48.40 & 139.07 & \\
1500.00 & 48.67 & 137.84 &
\end{tabular}

Table 4. ANOVA test on each LCU

\begin{tabular}{|c|c|c|c|c|c|c|c|c|}
\hline \multirow{2}{*}{ Sample } & \multicolumn{2}{|c|}{ Demi Plus } & \multicolumn{2}{|c|}{ Valo } & \multicolumn{2}{|c|}{ Woodpecker } & \multirow{2}{*}{$\mathrm{F}$} & \multirow{2}{*}{$\mathrm{p}$ value } \\
\hline & Mean & std & Mean & std & Mean & std & & \\
\hline Without & 1740.00 & 61.98 & 2800.00 & 0 & 1655.00 & 48.4 & 3948.52 & \multirow{8}{*}{$<0.01$} \\
\hline M1 & 392.50 & 40.64 & 1065.00 & 46.17 & 272.50 & 25.52 & 2468.79 & \\
\hline$M 2$ & 390.00 & 20.52 & 885.00 & 51.55 & 262.50 & 22.21 & 1816.13 & \\
\hline M3 & 430.00 & 25.13 & 990.00 & 41.68 & 305.00 & 22.36 & 2783.59 & \\
\hline M4 & 285.00 & 40.07 & 752.50 & 52.50 & 245.00 & 15.39 & 1038.80 & \\
\hline M5 & 235.00 & 23.51 & 587.50 & 45.52 & 200.00 & 0.00 & 1050.05 & \\
\hline M6 & 150.00 & 0.00 & 490.00 & 52.82 & 150.00 & 0.00 & 828.83 & \\
\hline M7 & 195.00 & 15.39 & 442.50 & 59.11 & 155.00 & 15.39 & 366.80 & \\
\hline
\end{tabular}


Table 5. Differences between composite-resin shade in Demi Plus LCU, Valo LCU and Woodpecker LCU

\begin{tabular}{|c|c|c|c|c|c|c|c|c|c|c|}
\hline \multirow[b]{2}{*}{ Sample } & \multirow[b]{2}{*}{$n$} & \multicolumn{3}{|c|}{$\begin{array}{l}\text { composite-resin shade in } \\
\text { Demi Plus LCU }\end{array}$} & \multicolumn{3}{|c|}{$\begin{array}{c}\text { composite-resin shade in } \\
\text { Valo LCU }\end{array}$} & \multicolumn{3}{|c|}{$\begin{array}{l}\text { composite-resin shade in } \\
\text { Woodpecker LCU }\end{array}$} \\
\hline & & Mean & std & $\mathrm{t}$ test & Mean & std & $\mathrm{t}$ test & Mean & std & $\mathrm{t}$ test \\
\hline$M 1-M 2$ & 20 & 37.50 & 31.93 & 5.25 & 180.00 & 49.74 & 16.19 & 25.00 & 25.65 & 4.36 \\
\hline$M 1-M 3$ & 20 & 37.50 & 35.82 & 4.68 & 75.00 & 47.30 & 7.09 & 32.50 & 37.26 & 3.90 \\
\hline$M 1-M 4$ & 20 & 107.50 & 56.84 & 8.46 & 312.50 & 48.33 & 28.92 & 27.50 & 25.52 & 4.82 \\
\hline M1-M5 & 20 & 157.50 & 33.54 & 21.00 & 477.50 & 47.23 & 45.22 & 72.50 & 25.52 & 12.70 \\
\hline$M 1-M 6$ & 20 & 242.50 & 40.64 & 26.69 & 575.00 & 47.30 & 54.37 & 122.50 & 25.52 & 21.47 \\
\hline M1-M7 & 20 & 197.50 & 44.35 & 19.91 & 622.50 & 49.93 & 55.75 & 117.50 & 29.36 & 17.90 \\
\hline$M 2-M 3$ & 20 & 40.00 & 30.78 & 5.81 & 105.00 & 27.63 & 17.00 & 47.50 & 25.52 & 8.32 \\
\hline$M 2-M 4$ & 20 & 105.00 & 39.40 & 11.92 & 132.50 & 29.36 & 20.18 & 17.50 & 24.47 & 3.20 \\
\hline M2-M5 & 20 & 240.00 & 20.52 & 52.31 & 395.00 & 15.39 & 114.78 & 112.50 & 22.21 & 22.65 \\
\hline$M 2-M 6$ & 20 & 240.00 & 20.52 & 52.31 & 395.00 & 15.39 & 114.78 & 112.50 & 22.21 & 22.65 \\
\hline$M 2-M 7$ & 20 & 195.00 & 27.63 & 31.57 & 442.50 & 37.26 & 53.11 & 107.50 & 18.32 & 26.25 \\
\hline M3-M4 & 20 & 145.00 & 42.61 & 15.22 & 237.50 & 31.93 & 33.26 & 60.00 & 26.16 & 10.26 \\
\hline M3-M5 & 20 & 195.00 & 32.04 & 27.22 & 402.50 & 19.70 & 91.36 & 105.00 & 22.36 & 21.00 \\
\hline M3-M6 & 20 & 280.00 & 25.13 & 49.83 & 500.00 & 32.44 & 68.92 & 155.00 & 22.36 & 31.00 \\
\hline M3-M7 & 20 & 235.00 & 28.56 & 36.80 & 547.50 & 37.96 & 64.51 & 150.00 & 32.44 & 20.68 \\
\hline M4-M5 & 20 & 50.00 & 53.80 & 4.16 & 165.00 & 28.56 & 25.84 & 45.00 & 15.39 & 13.08 \\
\hline M4-M6 & 20 & 135.00 & 40.07 & 15.07 & 262.50 & 27.51 & 42.68 & 95.00 & 15.39 & 27.61 \\
\hline M4-M7 & 20 & 90.00 & 44.72 & 9.00 & 310.00 & 34.79 & 39.85 & 90.00 & 20.52 & 19.62 \\
\hline M5-M6 & 20 & 85.00 & 23.51 & 16.17 & 97.50 & 34.32 & 12.71 & 50.00 & 0.00 & 223.61 \\
\hline M5-M7 & 20 & 40.00 & 30.78 & 5.81 & 145.00 & 27.63 & 23.47 & 45.00 & 15.39 & 13.08 \\
\hline M6-M7 & 20 & 45.00 & 15.39 & 13.08 & 47.50 & 37.96 & 5.60 & 5.00 & 15.39 & $1.45^{* *}$ \\
\hline
\end{tabular}

decreased significantly. Our studies (Table 1-5) has found statistically significant differences between the LCU (Without barrier and with the barrier). Table 8 show that shade M6-M7 in Woodpecker LCU has no significant result statistically. ANOVA test show significant result with $\mathrm{p}<0.01$ (Table 4) for comparing the all LCU to penetrate the barrier.

\section{DISCUSSION}

Insufficient light curing unit intensity were happen in all around the world. Marovic ${ }^{14}$, reported that several studies shown an improvement of Light Curing Unit qualities. Eventhough, some part of them are not working appropriately and need to be checked regularly. The easiest way to check is using radiometer but these device are known to be innacurate. ${ }^{14-16}$ There's many radiometer that dentist could use for checking the LCU intensity such as Bluephase (Ivoclar Inc.), Demetron radiometer (Kerr Inc.) and else. In this report the MaxLED radiometer was used.
This reports showed that composite thickness will reduce the capability of light curing unit to penetrate the composite. The shade of composite in between $M 1, M 2, M 3, M 4, M 5, M 6$ and $M 7$ also showed significant result in reducing the capability of LCU to penetrate in each shade. LCU output intensity was decrease more significant on M6 and M7 shade except on woodpecker LCU. 'Based on Jadhav ${ }^{17}$ report, it was found that shade, thickness, material composition, light intensity, wavelength, exposured duration, size, location and even orientation of the LCU tip are factors that affecting polymerization of resin composite. ${ }^{17}$ Thome $^{18}$ reported that the darker shades of resin composite the longer of light activation time needed. ${ }^{18}$ Both of $M 6$ and M7 resin composite has darker shade than the others composite barriers. It could be a reason why light curing unit output intensity on these shades barrier was lower than others(Table 6-8). Several report support this possibility. 19,20

Table 5 also showed that the barrier could 
give significant result in according to reduce the light intensity of all LCU. Valo LCU has the highest capability to penetrate the barriers and the LED.C LCU has the lowest mean value (Table 5). That condition made Valo LCU is the best LCU for polymerizing resin composite in this research. $M{ }^{11}$, reported that at least need $300 \mathrm{~mW} / \mathrm{cm}^{2}$ light intensity to cure $1 \mathrm{~mm}$ thickness of resin composite. $\mathrm{Garcia}^{20}$ has reported that need at least $600 \mathrm{~mW} / \mathrm{cm}^{2}$ power density to ensure $400 \mathrm{~mW} / \mathrm{cm}^{2}$ reaches the first increment of resin composite. All light cure unit in this report has output more than $300 \mathrm{~mW} / \mathrm{cm}^{2}$ as measured by our radiometer. That means all the LCU in this study has enough power to polymerize the resin composite. Furthermore, the clinician can add longer curing time for better polymerization. ${ }^{21}$

Our research showed that the change of orientation LCU tip could give a different value on radiometer, especially Demi Light and LED.C that have a tip in the unit. Jadhav ${ }^{17}$ has reported that the orientation tip could be a factor that contribute to polymerization failure of resin composite. Our radiometer confirmed that it could be a factor for failure polymerization. Lima $^{21}$ reported that its not only closest to the tip of the LCU, but also should throughout the entire resin composite. It means that the clinician should aware with this condition if they want to get better polymerization.

Valo LCU (Table 1 and 2) has the highest output intensity $\left( \pm 2800 \mathrm{~mW} / \mathrm{cm}^{2}\right)$ and highest mean value on each color shade (Table 5). Meanwhile, LED.C LCU has the lowest value (Table 5). To compensate the lowest intensity, the clinician suggested to give longer curing time. ${ }^{18,21,22}$

Ceballos $^{22}$ reported that resin composite also influenced by depth of cure. Maximal depth that recommended for resin composite is 2.5 $\mathrm{mm}$. Others study reported that the optimum thickness for resin composite is about 1-2 mm. ${ }^{20}$ Our study showed that in $2 \mathrm{~mm}$ thickness all LCU light intensity could penetrate to the bottom of the specimen.

The optimum distance between light and resin is less than $1 \mathrm{~mm}$ with the light positioned at 90 degrees from the composite surface. ${ }^{18,20}$ Our examination have tried to put the tip on the right direction and as close as to the specimen surface. Nevertheless, table 8 showed that the LED.C has no significant result statistically for M6-M7 shade $(p>0.01)$. both of this shade are the darker composition, and that maybe give similar result statistically and could be caused by the lowest intensity that come from the LED.C.

Intensity of curing light is performed by radiometer and can differ in wavelength detected. They also can be adjusted for the measurement of QTH or LED devices. The diameter the circular light sources also depend to the manufacture. ${ }^{14}$ Our radiometer has a wide mess around $8 \mathrm{~mm}$ and could be used for QTH and LED. However, the Bluephase meter (Ivoclar ${ }^{\mathrm{MM}}$ ) and Cure Rite (Dentsply ${ }^{\top M}$ ) are more closed to the gold standard to check the power intensity of LCU and we believe to try to compare to both of that radiometers in the future.

\section{CONCLUSION}

Light curing unit penetration capability to composite-resin barriers was depend on the origin power of LCU output intensity itself. The highest output intensity of LCU would give better result for resin composite polymerization. These findings may have an important message to any practitioners to check their LCU output intensity regularly at least using the radiometer.

\section{ACKNOWLEDGMENT}

The author would like to thanks Berniek Maskun for the statistical analytics support.

\section{REFERENCES}

1. Committee, O. \& Council, R. Guideline on pediatric restorative dentistry. Pediatr. Dent. 34, 173-80 (2012).

2. Zoergiebel, J. \& Ilie, N. Evaluation of a conventional glass ionomer cement with new zinc formulation: Effect of coating, aging and storage agents. Clin. Oral Investig. 17, 619626 (2012).

3. Yaman, B. C. et al. The effects of halogen and light-emitting diode light curing on the depth of cure and surface microhardness of composite resins. J. Conserv. Dent. 14, 136139 (2011).

4. Micali, B. \& Basting, R. T. Effectiveness of composite resin polymerization using light- 
emitting diodes ( LEDs ) or halogen-based light-curing units Efetividade de polimerização de uma resina composta fotopolimerizada por diodos emissores de luz ( LEDs ) ou luz. 18, (2004).

5. Kamal Nabhi, Ajay Chhabra, Varun Jindal, D. To Determinde the functional efficacy of LED units in various clinical offices. Dent. J. Adv. Stud. 3, 34-38 (2015).

6. Giorgi, M. C. C. \& Paulillo, L. A. M. S. Knoop hardness of composites cured with halogen and led light-curing units in class I restorations. Brazilian J. Oral Sci. 8, 30-33 (2009).

7. Vivek Hegde, S. J. \& Aher, G. B. A clinical survey of the output intensity of 200 light curing units in dental offices across Maharashtra. J. Conserv. Dent. 12, 105-108 (2009).

8. El-Mowafy, O., El-Badrawy, W., Wasef, M., Omar, H. \& Kermanshahi, S. Efficacy of new LED light-curing units in hardening of Class II composite restorations. J. Can. Dent. Assoc. (Tor). 73, 253a-253e (2007).

9. Burgess, J. O., Walker, R. \& Davidson, J. M. Posterior resin-based composite : review of the literature. Pediatr. Dent. 24, 465-479 (2002).

10. Shortall, A., El-Mahy, W., Stewardson, D., Addison, O. \& Palin, W. Initial fracture resistance and curing temperature rise of ten contemporary resin-based composites with increasing radiant exposure. J. Dent. 41, 45563 (2013).

11. Mahn, E. Clinical criteria for the successful curing of composite materials. Rev. Clin. Periodoncia Implant. Rehabil. Oral Vol. 6, 148-153 (2013).

12. Randolph, L. D. et al. Ultra-fast light-curing resin composite with increased conversion and reduced monomer elution. Dent. Mater. 30, 594-604 (2014).

13. Vijaya Kumar, C. N., Gururaj, M., Paul, J., Krishnaprasada, L. \& Divyashree, R. A comparative evaluation of curing depth and compressive strength of dental composite cured with halogen light curing unit and blue light emitting diode: An in vitro study. J. Contemp. Dent. Pract. 13, 834-837 (2012).

14. Marovic, D. et al. Time Dependent Accuracy of Dental Radiometers. Acta Clin. Croat. 52, 173-180 (2013).

15. Federlin, M. \& Price, R. Improving light-curing instruction in dental school. J. Dent. Educ. 77, 764-72 (2013).

16. Price, R. B., Labrie, D., Whalen, J. M. \& Felix, C. M. Effect of distance on irradiance and beam homogeneity from 4 light-emitting diode curing units. J. Can. Dent. Assoc. (Tor). 77, b9 (2011).

17. Jadhav, S., Aher, G., Hegde, V. \& Fajandar, $N$. Influence of light curing units on failure of directcomposite restorations. J. Conserv. Dent. 14, 225 (2011).

18. Thomé, T., Steagall, W., Tachibana, A., Braga, S. R. M. \& Turbino, M. L. Influence of the Distance of the Curing Light Source and Composite Shade on Hardness of Two Composites. J. Appl. Oral Sci. 15, 486-91 (2007).

19. Mohammed, A. \& Ario, S. Resin-Based Composite and LCU-related Factors Affecting the Degree of Cure. A Literature Review: Part 2. Light Curing Units \& Related Factors. Acta Medica Marisiensis 61, 255-260 (2015).

20. Hervás-García, A., Martínez-Lozano, M. A., Cabanes-Vila, J., Barjau-Escribano, A. \& FosGalve, P. Composite resins. A review of the materials and clinical indications. Med. oral, Patol. oral y cirugía bucal. 11, 215-220 (2006).

21. Lima, A. F. et al. Influence of light source and extended time of curing on microhardness and degree of conversion of different regions of a nanofilled composite resin. Eur. J. Dent. 6, 153-157 (2012).

22. Ceballos, L. et al. Curing effectiveness of resin composites at different exposure times using LED and halogen units. Med. Oral Patol. Oral Cir. Bucal 14, 3-8 (2009). 